\section{Time-distance records and the power function}

\author{
A. H. HARRIS
}

Department of Psychiatry and Behavioral Science

Johns Hopkins University School of Medicine, Baltimore, Maryland 21205

World record performances in running, walking, swimming, speed skating, and horse racing are closely described by a function of the form $y=a x^{b}$. In addition, all the functions have approximately the same exponent! These data are discussed in relation to S. S. Stevens's sensory power law as a type of complex case of cross-modality matching, and it is suggested that the power function describes a more general behavioral process which necessarily includes sensory discriminations.

Over the past two decades, S. S. Stevens has championed a sensory power law, which describes "the operating characteristic of the sensory system [Stevens, 1961]." According to this law, when humans are asked to "scale" sensory continua by making sensory magnitude judgments, the subjective magnitudes correspond to the physical magnitudes according to the function form $y=a x^{b}$, where $y$ is the magnitude of the subjective sensation, $x$ is the physical stimulus magnitude, and $a$ and $b$ are values which depend upon the particular sense modality described. The present paper introduces a motor power law which holds for several types of motor performance and maintains the same exponent across all of these motor behaviors.

World records, for as long as they last, may be regarded as limiting values of human (animal) performance. As such, they may provide information about the functional characteristics of the human system as do threshold determinations of other sensory or motor skills (e.g., visual acuity, reaction time). Since world records are already in quantitative form, one need only find a continuum to examine for lawful relationships. Such a continuum is present for time-distance records. This paper will examine how world record time varies as a function of distance for the activities of running, walking, swimming, speed skating, and horse racing. The Ss, of course, were men, women, and horses in their respective events, and the data were obtained from the Guinness Book of World Records (McWhirter \& MeWhirter, 1968, 1971). These data were plotted on $\log -\log$ coordinates, examined for linearity, and the least-squares regression lines were calculated. The results are shown in Fig. 1. All the functions are closely linear and parallel, with slopes of 1.1 and average errors (difference between predicted and obtained values) generally less than 3\%. The calculated log-log functions and percent average errors are listed in Table 1.

$A$ precise interpretation of this indicate power functions. (which, to continue the analogy, are like two puzzle pieces which fit each other but not yet the larger body of assembled pieces), although at first glance, judging the brightness of a light seems very different from running a mile. Common to all the time-distance motor events is a technique known as "pacing," where the runner (or skater, jockey, etc.) makes a complex judgment of time and distance and then adjusts his speed in order to maximize performance (minimize time). The judgment (sensory scaling) of these continua yields the same exponent as found in the motor power law, namely, $1.1 !^{1}$ If this convergence accounts in some sense for the motor power law, then one might expect it to apply similarly in other motor performance situations, since most, if not all, learned motor behavior intimately involves sensory discriminations. ${ }^{2}$ The complex relationship, for example, between sensory and motor processes which is described by the term "learning" might also be expected to show the power function form, and there are already data to support this possibility (Stevens, J.C., \& Savin, 1962). Since all the data share in common the measurement of behavior, perhaps a

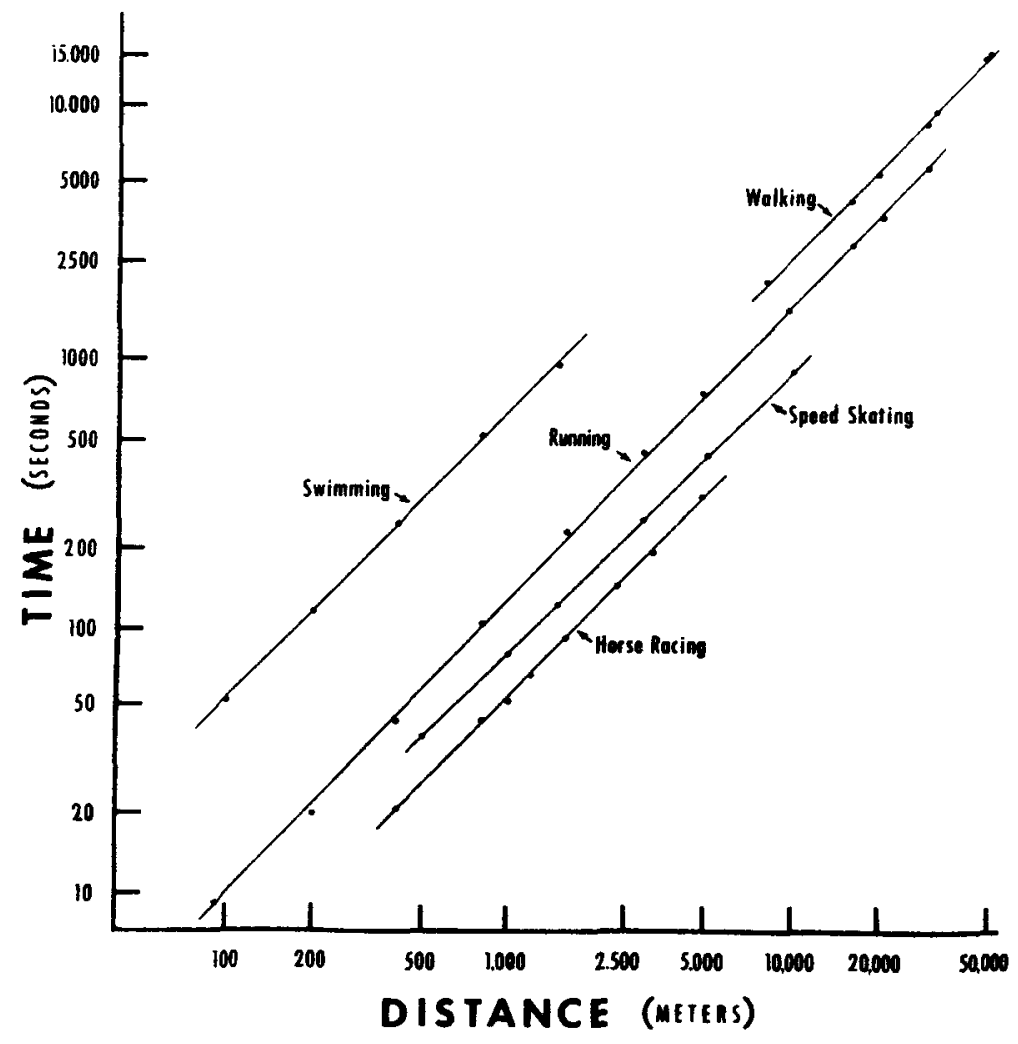

Fig. 1. World-record time plotted against distance for running, walking, swimming, speed skating, and horse racing. Straight lines on log-log coordinates 
Table 1

Log-Log Functions and Percent Average Error for Time-Distance Records in Running, Walking, Swimming. Speed Skating, and Horse Racing

\begin{tabular}{|c|c|c|}
\hline Event & $\begin{array}{l}\text { Log-Log } \\
\text { Function }\end{array}$ & $\begin{array}{c}\text { Percent Average } \\
\text { Error Between } \\
\text { Predicted and } \\
\text { Obtained Data }\end{array}$ \\
\hline \multicolumn{3}{|l|}{ Running } \\
\hline Men & $Y=1.11 X-2.94$ & 3.6 \\
\hline Women* & $Y=1.13 X-2.88$ & $\mathbf{5 . 3}$ \\
\hline \multicolumn{3}{|l|}{ Swimming } \\
\hline Men & $\mathbf{Y}=1.09 X-1.10$ & 2.1 \\
\hline Women* & $Y=1.07 X-0.94$ & 2.3 \\
\hline \multicolumn{3}{|l|}{ Speed Skating } \\
\hline Men & $Y=1.06 X-3.00$ & 0.6 \\
\hline Women* & $Y=1.09 X-3.15$ & 2.7 \\
\hline \multicolumn{3}{|l|}{ Walking } \\
\hline Men & $Y=1.09 x-2.34$ & 2.1 \\
\hline \multicolumn{3}{|l|}{ Horse Racing } \\
\hline Men & $Y=1.09 X-3.61$ & 1.7 \\
\hline
\end{tabular}

*Not plotted in Figure 1

power function describes some more general behavior principle which includes those special cases involving learning curves, sensory scaling, and time-distance performances.

\section{REFERENCES}

HERRNSTEIN R J \& VAN SOMMERS

P. Method for sensory scaling with animals, Science, $1962,135,40-41$.

MCWHIRTER, N., \& McWHIRTER, R. Guinness book of world records. New York: Bantam, 1968, 1971.

STEVENS, S. S, On the psychophysical law. Psychological Review, 1957, 64, 153-181. STEVENS, S. S. To honor Fechner and repeal his law. Science, 1961, 133, 80-96. STEVENS, S. S. Neural events and the psychophysical law. Science, 1970, 170, 1043-1050.
STEVENS, J. C., \& SAVIN, H. B. On the form of learning curves. Journal of the Experimental Analysis of Behavior, 1962 5, 15-18.

\section{NOTES}

1. S. S. Stevens has spoken of the "noisy" measurements from which the exponents derive, and over the years has corrected the values of certain exponents. In 1957 (Stevens, 1957), the exponent for visual length was 1.1, the exponent for duration was listed as between 1.05 and 1.2 , and the exponent for visual distance was 0.67. This latter exponent was based upon a single study, whereas the former two were each based upon the results of three separate experiments. In 1970 (Stevens, 1970), the exponent for visual length was 1.0 and for duration was 1.1. The visual distance continuum was not included among the 18 continua listed.

2. S. S. Stevens (Stevens, 1970) reports t're doctoral thesis of R. J. W. Mansfield, Harvard, 1970 (in which it was found that reaction time to visual stimulation was directly proportional to subjective brightness), as evidence that "the velocity of the visual reaction, measured either behaviorally or neurelectrically is directly proportional to subjective brightness [italics mine]." See also Herrnstein and Van Sommers (1962).

(Received for publication February 14 1972; revision received June 30, 1972. 